\title{
False traumatic aneurysm of the aortic arch. Retrograde cerebral perfusion obliged. A case report.
}

\author{
Michel F. Mitsomoy, MD, ${ }^{\mathrm{a}}$ Reddy Atipo-Galloye, MD, ${ }^{\mathrm{a}}$ Borgatia D. Atta, MD, ${ }^{\mathrm{b}}$ and Rochd Sayah, PhD, ${ }^{\mathrm{c}}$ \\ Rabat, Morocco
}

The possibility of finding difficulties can modify the beginning technique of brain protection and must be always taken in account during aortic arch surgery. That was the situation in our case report. Several surgical difficulties were found that factored into changing our beginning technique of brain protection, and neurologic postsurgical complications caused the death of the patient.

\section{BACKGROUND}

Surgery of the aortic arch aneurysm presents 2 fundamental challenges: Cerebral perfusion and myocardial protection. False aneurysms of the traumatic aortic arch are rare, and $2 \%$ to $5 \%$ of patients with aortic injury develop false aneurisms. ${ }^{1}$ The basic technique of cerebral protection is deep hypothermic circulatory arrest, which can (or cannot) be combined with selective anterior perfusion or retrograde cerebral perfusion $(\mathrm{RCP}){ }^{2,3}$ The best results are obtained by combining moderate hypothermic circulatory arrest and selective anterior perfusion. ${ }^{3,4}$ We present

From the Department of Cardiovascular Surgery, ${ }^{a}$ Cheikh Zaid Hospital, University Mohamed V, Rabat, Morocco; and the Departments of Cardiology ${ }^{\mathrm{b}}$ and Cardiovascular Surgery, ${ }^{\mathrm{c}}$ Ibn Sina Hospital, University Mohamed V, Rabat, Morocco. Disclosures: Authors have nothing to disclose with regard to commercial support. Received for publication Aug 14, 2012; accepted for publication Aug 21, 2012; available ahead of print Oct 8, 2012.

Address for reprints: Michel F. Mitsomoy, MD, Amal 5, No. 1555 CYM, Rabat, Morocco (E-mail: mitsomoy@gmail.com).

J Thorac Cardiovasc Surg 2013;145:e1-2

$0022-5223 / \$ 36.00$

Crown Copyright (c) 2013 Published by Elsevier Inc. on behalf of The American Association for Thoracic Surgery

http://dx.doi.org/10.1016/j.jtcvs.2012.08.051 a patient who received an RCP. The technical difficulties encountered were the factors that obliged us to use this technique.

\section{CLINICAL SUMMARY}

A 35-year-old patient had a history of chest trauma that occurred 5 years ago. For 2 years, he complained of chest pain. In the past 6 months, the patient began to present facial edema. Clinical examination confirmed the facial edema and revealed a mass at the base of the neck, which was pulsatile and synchronous with the arterial pulse. The rest of the examination was unremarkable.

Chest x-ray showed cardiomegaly and enlargement of the upper mediastinum. Computed tomography angiography found a false aneurysm of the arch, $85 \times 101 \times 150 \mathrm{~mm}$ with a 75-mm collar, with a partial thrombosis. The aneurysm was compressing the superior vena cava. It was in contact with the sternum (Figure 1). The patient was operated under cardiopulmonary bypass with femoral-femoral cannulation. The partial rupture of the aneurysm after median sternotomy, and the difficulty of accessing the supraaortic trunks, precipitated the establishment of an RCP to protect the brain. The patient was in the Trendelenburg position with external head cooling under moderate hypothermia $\left(28^{\circ} \mathrm{C}\right)$.

Inotropic-positive drugs were used at the end of the cardiopulmonary bypass. The immediate postoperative course was marked by bilateral mydriasas, hyperthermia, hyperglycemia, hyperleukocytosis, and elevated protein $\mathrm{C}$ levels. Computed tomography scan showed diffuse

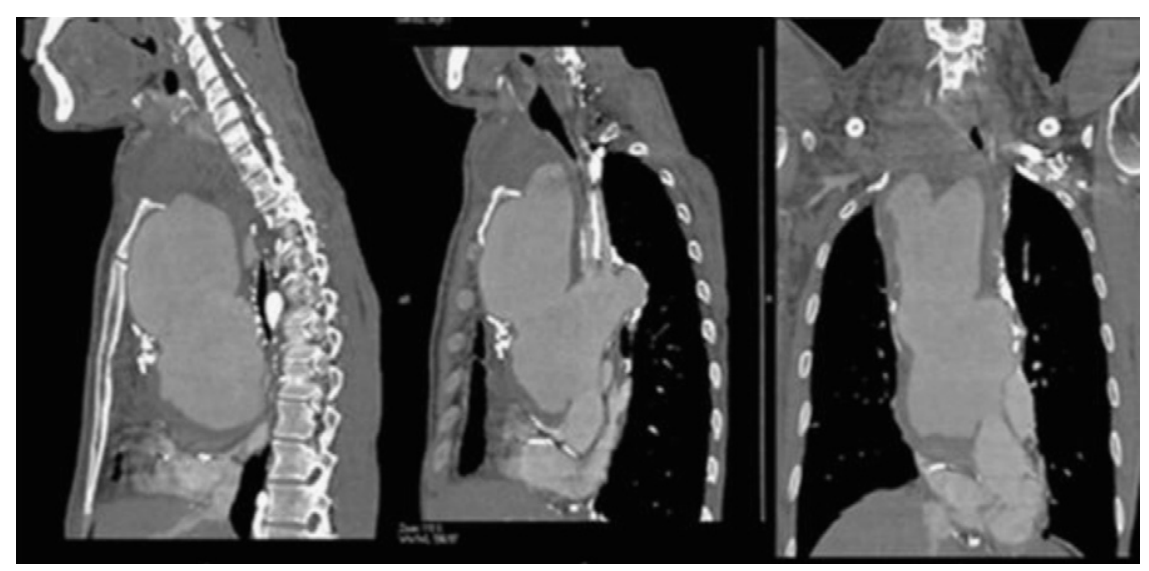

FIGURE 1. Left, False aneurysm in contact with sternum. Center and right, Frontal sections showing the extent of the aneurysm. 


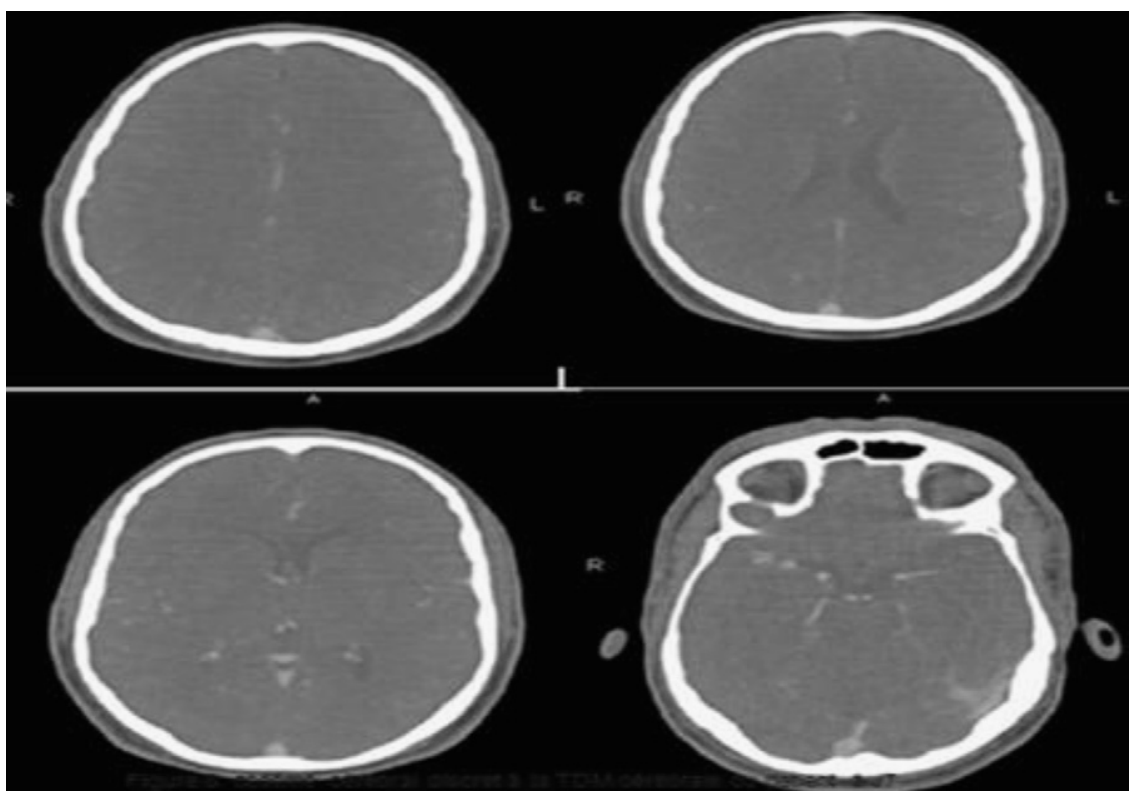

FIGURE 2. Diffuse cerebral edema.

cerebral edema (Figure 2). Generalized seizures occurred on the fourth day. Despite resuscitation, the patient died 10 days after surgery for the neurologic disorders.

\section{DISCUSSION}

The technique of cerebral protection can be divided into 2 groups: Deep hypothermic circulatory arrest with or without RCP and selective antegrade cerebral perfusion $(\mathrm{SACP}){ }^{2,3}$ Initially, RCP was considered the original way to avoid cerebral artery injuries, especially with the presumption that brain damage would be avoided with a venous pressure of $25 \mathrm{~mm} \mathrm{Hg} .{ }^{5}$ SACP extends circulatory arrest while maintaining physiologic brain perfusion, with less neurologic dysfunction, but the safety of this technique remains limited. ${ }^{5}$ The ideal technique of cerebral protection in aortic arch surgery is still controversial; however, in recent years new protocols in cerebral protection have emerged.

Moderate hypothermic circulatory arrest combined with SACP is an appropriate means of preventing neurologic dysfunction and gives the best results. ${ }^{5}$ Many authors consider SACP the best option for brain protection. ${ }^{3-5}$ In our patient, the aneurysm extensions, partial rupture after sternotomy, and difficulties associated with exposing supra-aortic artery trunks were factors that forced us to use RCP.
Neurologic complications associated with continuous RCP pressure have been described. ${ }^{3,4}$ However, Kubota and colleagues ${ }^{5}$ showed that the new protocol of brain perfusion with moderate hypothermia associated with RCP and intermittently modulated pressure $(15 \mathrm{~mm} \mathrm{Hg}$ for $30 \mathrm{sec}-$ onds alternated with $45 \mathrm{~mm} \mathrm{Hg}$ for 60 seconds) reduces postoperative neurologic complications.

\section{CONCLUSIONS}

Continuous RCP was not the best option for brain protection in our patient, but intraoperative difficulties forced us to use RCP. The new protocol of RCP applied by some authors seems to be a safe option to protect the brain.

\section{References}

1. Bennett DE, Cherry JK. The natural history of traumatic aneurysms of the aorta. Surgery. 1967;61:516-23.

2. Lu S, Sun X, Hong T, Yang S, Song K, Lai H, et al. Bilateral versus unilateral antegrade cerebral perfusion in arch reconstruction for aortic dissection. Ann Thorac Surg. 2012;93:1917-20.

3. Lai WL, Hsu CP, Shih CC, Li ML, Li PC. Selective cerebral perfusion with 4-branch graft aortic arch replacement total: outcomes in 12 patients. J Cardiothorac Surg. 2012;7:32.

4. Khaladj N, Shrestha M, Meck S, Peterss S, Kamiya H, Kallenbach K, et al. Hypothermic circulatory arrest with selective antegrade cerebral perfusion in ascending aortic and aortic arch surgery: a risk factor analysis for adverse outcome in 501 patients. J Thorac Cardiovasc Surg. 2008;135:908-14.

5. Kubota H, Takamoto S, Yoshino H, Kitahori K, Kawata M, Tonari K, et al. Clinical application of intermittent pressure-augmented retrograde cerebral perfusion. Ann Thorac Surg. 2010;90:1340-3. 